\title{
Inclusive dyslexia-friendly collaborative online learning environment: Malaysia case study
}

\author{
Loren Pang $^{1}$ (D) Chen Chwen Jen ${ }^{1}$
}

Received: 8 June 2017 / Accepted: 13 September 2017

(C) Springer Science+Business Media, LLC 2017

\begin{abstract}
Currently available web page accessibility guidelines focus more on reading and writing, with inadequate attention to other aspects of online learning such as computer-mediated communication. This study aims to explore the engagement of Malaysia secondary school students with dyslexia and students without dyslexia on various synchronous and asynchronous communication interaction technologies in an online collaborative learning environment. Multiple case within subject qualitative study was employed to investigate the engagement of students using a semi structured interview guideline. The findings revealed that (1) text chat is unsuitable for learning discussion for all learners, (2) forum affords self-paced and organized formal discussion for most learners and (3) video conferencing is suitable for interactive face-to-face, verbal discussion for most learners.
\end{abstract}

Keywords Dyslexia Engagement - Accessibility - Synchronous communication · Asynchronous communication · Online learning

\section{Introduction}

Learning is not restricted to traditional classroom settings with the implementation of online learning. Web page accessibility is one of the success factors for implementing online learning in Malaysia, besides learner's participation, interactivity of a learning environment, content presentation and design (Goi and Ng 2009). Although dyslexia occurs independently of intelligence, dyslexia cannot be cured which means the problem faced will continue to occur throughout the life span (British Dyslexia Association 2007). However, the existing web page accessibility guidelines emphasize

Loren Pang

lorenpang@live.com

1 Faculty of Cognitive Sciences and Human Development, Universiti Malaysia Sarawak, 94300 Kota Samarahan, Sarawak, Malaysia 